\title{
OVERVIEW OF CRITICAL FACTORS AFFECTING MEDICAL USER INTERFACES IN INTENSIVE CARE UNIT (ICU)
}

\author{
Ganesh Bhutkar ${ }^{1}$, Dinesh Katre ${ }^{2}$ and Shahaji Deshmukh ${ }^{3}$ \\ ${ }^{1} \mathrm{PhD}$ Research Scholar, IIT Bombay \& Assistant Professor, VIT, Pune, India \\ ${ }^{2}$ Associate Director and Head, HCDC Group, C-DAC, Pune, India \\ ${ }^{3}$ Professor, Department of Surgery, BVUMC, Pune, India
}

\begin{abstract}
This paper provides a comprehensive overview of critical factors, which affect on-screen user interfaces of medical devices in Intensive Care Unit (ICU). A literature survey with relevant research publications has led to selection of thirty eight critical factors in ICU. The critical factors identified are categorized into various groups based on three major aspects - system evaluation parameters, constituents of patient management and user interface design. Physicians' survey, in which five physicians are involved, is used to categorize the identified critical factors into related groups. In the process, fourteen critical factors are mainly selected, which affect on-screen user interface design of medical devices. The applicability of such factors is demonstrated with the help of a case study of head-injury patient admitted in ICU. The critical factors identified are definitely useful to device manufacturers, user interface designers, ICU administrators and physicians for improved device design, ICU resource management and patient care.
\end{abstract}

\section{KEYWORDS}

Critical Factors, Intensive Care Unit, Medical Devices, Medical User Interface, Survey

\section{INTRODUCTION}

Intensive Care Unit (ICU) is a specially nursing unit designed, equipped and staffed with skilled medical staff for critically-ill patients [1]. It is a cognitively complex environment like the cockpit of an aircraft or the operating room of a nuclear power plant $[2,3]$, where one is required to:

- attend critically-ill patients;

- monitor various medical devices and healthcare systems;

- integrate and understand complex information or patient records;

- judge the dynamically evolving situations and

- make quick and accurate diagnosis or decisions.

Medical User Interface (UI) is a UI of medical device or healthcare application. It is touch screen interface or Graphical User Interface (GUI) along with button / knob controls. It acts as a medium of interaction between physicians and medical devices. There are a variety of medical devices such as ventilator system, electrocardiogram (ECG) machine, infusion pump, patient monitoring system, defibrillator and ultrasonography machine, which are used for patient care in ICU. Figure 1 shows 8.4" TFT monitor with graphical user interface of patient monitoring system. Many of such medical devices have on-screen user interfaces for communication with medical users 
namely specialists, ICU physicians, resident doctors, interns or nursing staff - brothers / sisters [4]. The user interfaces of medical devices display vital information related with critically-ill patients [5]. This information includes numeric values, icons, options, menus, messages, graphs, tables or alerts. A miscommunication during such interaction can generate medical errors which may lead to injuries or deaths of patients [3]. ICU is a cognitively complex environment, involving various critical factors which affect the activities like interaction with medical devices. Therefore, there is a need to incorporate such critical factors in user interface design of medical devices to reduce possible medical errors.

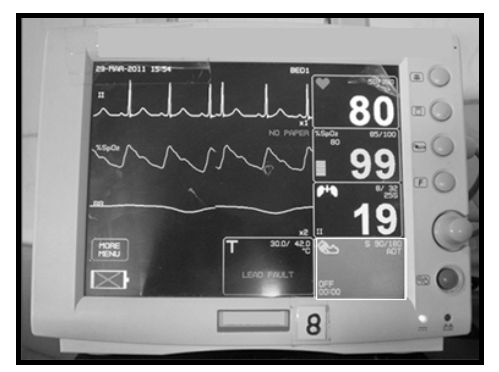

Figure 1. On-screen Graphical User Interface (GUI) of patient monitoring system

The following are the major questions addressed during research related with critical factors in ICU:

- Which are the critical factors related to ICU?

- How are identified critical factors categorized?

- Which of these critical factors affect on-screen user interface design of medical devices?

\section{RESEARCH METHODOLOGY}

This review-based study of critical factors in ICU includes major two activities - literature survey and physicians' survey. Initially, a thought was given to a field study of selected ICUs for identification of critical factors there. Such study might have identified few critical factors relevant to local ICU environment and would not have reflection of global perspective of critical care domain. Therefore, a better approach was thought of and that was in the form of a comprehensive literature survey of relevant publications. Such literature survey and associated physicians' survey are discussed ahead and a classification of critical factors has evolved through these activities. In the process, critical factors, which may affect on-screen user interface design of medical devices in ICU, are identified. At last, the applicability of these factors is demonstrated with the help of a case study.

\section{LITERATURE SURVEY}

The research publications highlighting various aspects such as patient records, alarm / alert design, adverse events, patient mortality, end-of-life care, ergonomic design and usability, clinical decision making, reporting process, nursing skills, nurse turnover, medical errors and other significant topics have been studied during the literature survey. These publications have been accessed through 'Google Scholar' using keywords such as 'critical factors', 'intensive care unit' and 'ICU'. Twenty seven research publications have been referred during this survey to study and to categorize critical factors relevant to ICU environment. These publications include twenty journal papers and other documents such as book chapters, committee reports and symposium / conference papers. A variety of critical factors have been identified during study of research 
publications and number of relevant discussions among the authors. The identified critical factors are represented in table 1 and they include factors related with medical devices, healthcare technology, users, patient care and work environment. Table 1 also provides a frequency depicting number of reviewed publications discussing each of related critical factors. The highest frequency is 7 for a critical factor - 'Interruptions \& distractions' and other six factors have frequency of atleast 5 . Eleven critical factors have the lowest frequency of just 1 . Thus, most of the critical factors in ICU are widely discussed in research publications considered in the review.

Table 1. List of critical factors in ICU along with a frequency depicting number of publications discussing related factors

\begin{tabular}{|c|c|c|c|c|c|}
\hline $\begin{array}{l}\text { Sr. } \\
\text { No. }\end{array}$ & Critical Factor & Freq. & $\begin{array}{l}\text { Sr. } \\
\text { No. }\end{array}$ & Critical Factor & Freq. \\
\hline 1 & Interruptions \& distractions & 7 & 20 & $\begin{array}{l}\text { Effectiveness of display / UI } \\
\text { design }\end{array}$ & 3 \\
\hline 2 & $\begin{array}{l}\text { Patients with chronic disease \& } \\
\text { long-term care }\end{array}$ & 6 & 21 & $\begin{array}{l}\text { Room layout \& location of } \\
\text { resources }\end{array}$ & 3 \\
\hline 3 & $\begin{array}{l}\text { Collaborative practice among } \\
\text { medical staff / teamwork }\end{array}$ & 5 & 22 & Ethical considerations & 2 \\
\hline 4 & $\begin{array}{l}\text { Urgent high-risk decision } \\
\text { making }\end{array}$ & 5 & 23 & Critical incident reporting & 2 \\
\hline 5 & $\begin{array}{l}\text { Level of arousal \& anxiety } \\
\text { (High or low) }\end{array}$ & 5 & 24 & $\begin{array}{l}\text { Litigious climate \& medical } \\
\text { malpractice claims }\end{array}$ & 2 \\
\hline 6 & Surveillance \& monitoring & 5 & 25 & $\begin{array}{l}\text { Familiarity of equipment, } \\
\text { procedure or environment }\end{array}$ & 2 \\
\hline 7 & $\begin{array}{l}\text { Physicians with varying levels } \\
\text { of critical care training }\end{array}$ & 5 & 26 & Availability of backup systems & 2 \\
\hline 8 & Design of alarms \& alerts & 4 & 27 & $\begin{array}{l}\text { Staff shortage \& high nurse } \\
\text { turnover }\end{array}$ & 2 \\
\hline 9 & $\begin{array}{l}\text { Organizational policies } \quad \& \\
\text { procedures }\end{array}$ & 4 & 28 & Restricted visitation & 1 \\
\hline 10 & Evidence-based practice & 4 & 29 & Information overload & 1 \\
\hline 11 & $\begin{array}{l}\text { Implications of shift work \& } \\
\text { internal rotation }\end{array}$ & 4 & 30 & $\begin{array}{l}\text { Availability of complete patient } \\
\text { record / EMR }\end{array}$ & 1 \\
\hline 12 & Equipment defect \& failure & 4 & 31 & $\begin{array}{l}\text { Complex work flow } \quad \& \\
\text { information flow }\end{array}$ & 1 \\
\hline 13 & 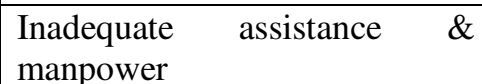 & 3 & 32 & Skills of nurses & 1 \\
\hline 14 & $\begin{array}{l}\text { Intense nature, haste \& pace of } \\
\text { work }\end{array}$ & 3 & 33 & $\begin{array}{l}\text { Type / amount / duration of } \\
\text { therapy }\end{array}$ & 1 \\
\hline 15 & Emergency & 3 & 34 & $\begin{array}{lll}\begin{array}{l}\text { Correctness } \\
\text { thresholds }\end{array} & \text { of } & \text { default } \\
\end{array}$ & 1 \\
\hline 16 & Hands-off at multiple levels & 3 & 35 & Situation-specific quick fixes & 1 \\
\hline 17 & Complex technology & 3 & 36 & $\begin{array}{l}\text { Maintenance of records \& } \\
\text { diaries }\end{array}$ & 1 \\
\hline 18 & Multitasking & 3 & 37 & Micro-culture of ICU & 1 \\
\hline 19 & Effect of environmental factors & 3 & 38 & Long working hours & 1 \\
\hline
\end{tabular}


Thirty eight critical factors in ICU have been identified as depicted in table 1 and there is a burning need to categorize them. A few critical factors are discussed ahead in brief:

- An 'Urgent high-risk decision-making' is an important critical factor, which is affected by perpetual narrowing and cognitive tunnelling among medical users - mainly physicians. Perceptual narrowing is an inability to attend all information sources that might be important for deciding on proper course of action. Cognitive tunnelling is tendency to focus on only one hypothesis or solution at a time and ignoring other possibilities [6].

- Another critical factor is 'Interruptions and disruptions', which include asking questions or for assistance, phone calls, exchange of information with others [7], presence of other patients, noise from medical devices and surrounding people [8].

- 'Effect of environmental factors' is also critical. These environmental factors include location, temperature, lighting condition, noise and surrounding devices / objects [9].

- 'Effectiveness of display / UI design' and 'Equipment defect and failure' are also important critical factors. They include issues such as right-handed design, legibility and contrast, clutters of features, lack of templates and intelligence, design of icons, alerts and alarms, user manuals in foreign languages, mobility and portability [2, 4].

- The 'Skills of nurses' is a critical factor, which affects a patient care in ICU. These skills include safe medication, patient monitoring, respiratory / orthopaedic care, record keeping, assistance to physicians, bed-making, pain management, hygiene, nutrition and patient / family counselling $[10,11]$.

\section{PHYSICIANS SURVEY}

Involvement of physicians has been essential in categorization of critical factors identified during literature survey. This survey has been targeted mainly at physicians serving in ICU such as specialists, ICU physicians and resident physicians. Five physicians have participated in this survey, which is a questionnaire-based survey. This survey is based on convenient sampling [12] and is primarily used in categorization of critical factors based on system evaluation parameters and user interface design. It is really hectic and tricky challenge to get access to busy ICU physicians [13] and make them to respond to such questionnaire, which has 38 critical factors. It has taken more than six weeks to collect responses to the questionnaire. The critical factors identified can be grouped in number of ways for further understanding and such categorization of critical factors is discussed in the next section.

\section{CATEGORIZATION OF CRITICAL FACTORS}

The critical factors identified in related survey are categorized into several groups focusing on various aspects. Three major aspects considered during such categorization include:

I. System evaluation parameters,

II. Constituents of patient management,

III. User interface design. 
This categorization of critical factors in ICU is discussed in next subsections with necessary details.

Table 2. Physicians' survey related with critical factors

\begin{tabular}{|c|c|c|c|c|c|}
\hline \multirow{2}{*}{$\begin{array}{l}\text { Sr. } \\
\text { No. }\end{array}$} & \multirow[t]{2}{*}{ Critical Factor } & \multicolumn{4}{|c|}{ Physicians' Response } \\
\hline & & $\mathbf{T}$ & $\mathbf{P}$ & $\mathrm{C}$ & $\mathbf{E}$ \\
\hline 1 & Inadequate assistance $\&$ manpower & 4 & 0 & 0 & 1 \\
\hline 2 & Intense nature, haste \& pace of work & 1 & 3 & 0 & 1 \\
\hline 3 & Emergency & 4 & 0 & 0 & 0 \\
\hline 4 & Restricted visitation & 2 & 0 & 0 & 3 \\
\hline 5 & Design of alarms \& alerts & 1 & 0 & 3 & 0 \\
\hline 6 & Collaborative practice among medical staff / teamwork & 0 & 1 & 0 & 4 \\
\hline 7 & Hands-off at multiple levels & 1 & 3 & 0 & 1 \\
\hline 8 & Complex technology & 4 & 1 & 0 & 1 \\
\hline 9 & Information overload & 1 & 0 & 4 & 0 \\
\hline 10 & Availability of complete patient record / EMR & 0 & 5 & 0 & 0 \\
\hline 11 & Urgent high-risk decision making & 4 & 0 & 1 & 0 \\
\hline 12 & Multitasking & 5 & 0 & 0 & 0 \\
\hline 13 & Level of arousal \& anxiety (High or low) & 0 & 0 & 0 & 5 \\
\hline 14 & Organizational policies \& procedures & 2 & 0 & 0 & 3 \\
\hline 15 & Evidence-based practice & 0 & 5 & 0 & 0 \\
\hline 16 & Complex work flow \& information flow & 0 & 0 & 5 & 0 \\
\hline 17 & Effect of environmental factors & 2 & 0 & 3 & 0 \\
\hline 18 & Implications of shift work \& internal rotation & 2 & 3 & 0 & 0 \\
\hline 19 & Skills of nurses & 0 & 0 & 1 & 4 \\
\hline 20 & Effectiveness of display / UI design & 0 & 0 & 5 & 0 \\
\hline 21 & Type / amount / duration of therapy & 0 & 2 & 0 & 3 \\
\hline 22 & Ethical considerations & 3 & 2 & 0 & 1 \\
\hline 23 & Critical incident reporting & 0 & 0 & 4 & 1 \\
\hline 24 & Room layout \& location of resources & 0 & 0 & 0 & 5 \\
\hline 25 & Correctness of default thresholds & 1 & 3 & 0 & 0 \\
\hline 26 & Patients with chronic disease $\&$ long-term care & 0 & 2 & 0 & 3 \\
\hline 27 & Litigious climate \& medical malpractice claims & 2 & 0 & 0 & 3 \\
\hline 28 & Surveillance \& monitoring & 0 & 0 & 4 & 1 \\
\hline 29 & Situation-specific quick fixes & 5 & 0 & 0 & 0 \\
\hline 30 & Familiarity of equipment, procedure or environment & 4 & 0 & 0 & 2 \\
\hline 31 & Availability of backup systems & 1 & 0 & 0 & 4 \\
\hline 32 & Maintenance of records \& diaries & 3 & 1 & 1 & 0 \\
\hline 33 & Physicians with varying levels of critical care training & 0 & 5 & 0 & 0 \\
\hline 34 & Staff shortage \& high nurse turnover & 0 & 0 & 0 & 5 \\
\hline 35 & Micro-culture of ICU & 0 & 0 & 0 & 4 \\
\hline 36 & Long working hours & 0 & 0 & 0 & 5 \\
\hline 37 & Interruptions \& distractions & 4 & 0 & 0 & 1 \\
\hline 38 & Equipment defect \& failure & 1 & 4 & 0 & 0 \\
\hline
\end{tabular}




\subsection{CATEGORIZATION BASED ON SYSTEM EVALUATION PARAMETERS IN ICU}

There are various system evaluation parameters such as response time, precision, comprehension, efficiency, reliability, availability or quality [14]. A first categorization of critical factors is based on system evaluation parameters such as response time, precision, comprehension and efficiency, which are imperative in critical environment like ICU as observed during field study. A response time is a time required responding to the patient condition or errors by physicians while using medical devices and healthcare technology in ICU [15]. A precision is an exactness of diagnosis and treatment. A comprehension is an ability to understand patient condition, diagnostic reports and monitoring parameters. Efficiency is a quality of being able to do a task successfully without wasting time or energy in ICU environment.

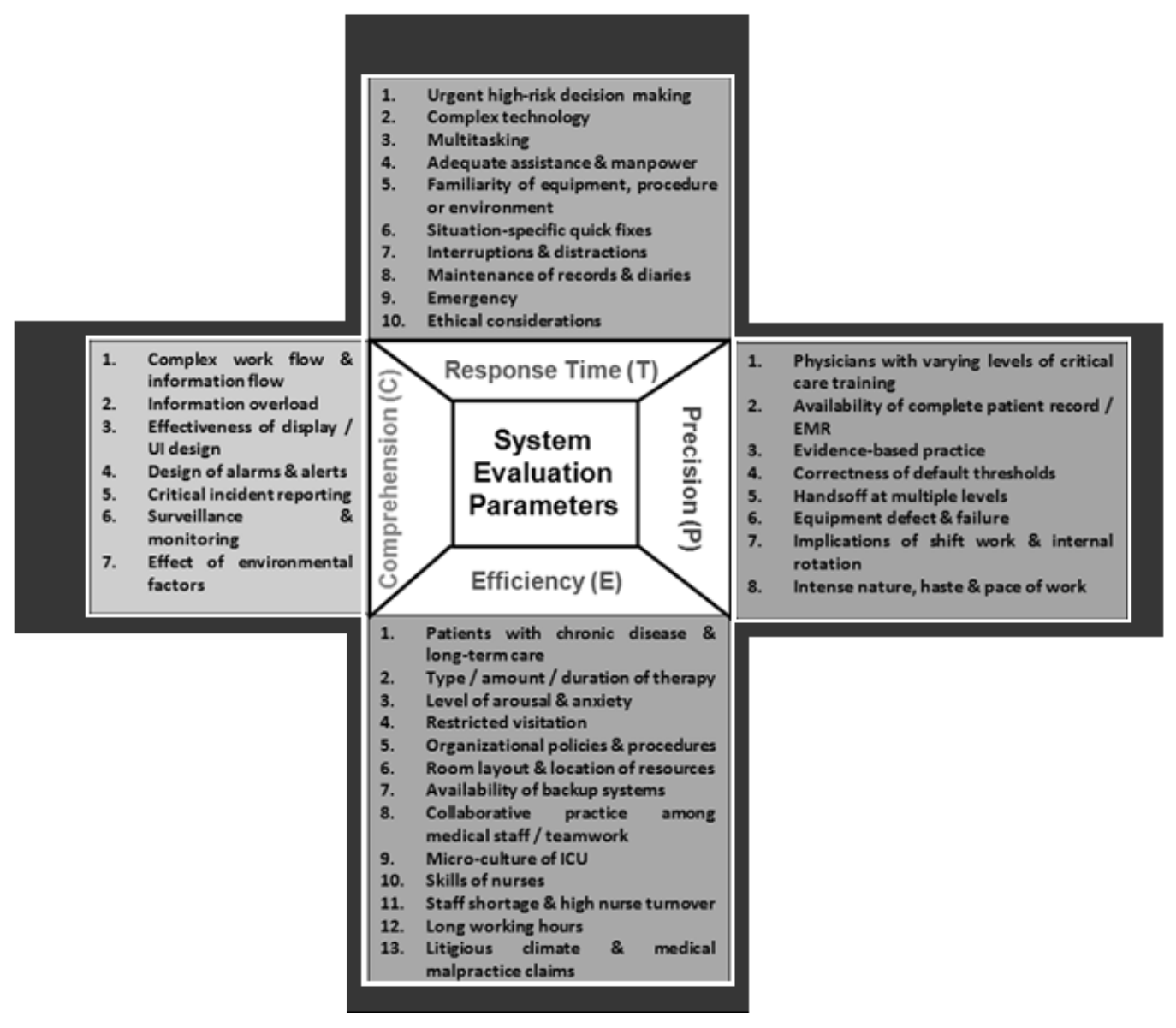

Figure 2. Categorization of critical factors based on system evaluation parameters

In physicians' survey, a questionnaire is prepared with a major focus on these four system parameters. Here, physicians are asked to select an appropriate parameter for each of the critical factors. The data collected through such physicians' survey is aggregated in table 2 , which depicts preferences of physicians for each critical factor in terms of relevant system evaluation parameters. Each row of this table shows physicians' preferences for related critical factor and the 
maximum value in a specific row indicates about associated evaluation parameter for each critical factor. Such evaluation parameter is its category and is also depicted with a grey color. For example, a row for a factor 'Inadequate assistance \& manpower' shows value - four for response time and one for efficiency, in which four is maximum value. Therefore, this factor is categorized under response time. A detailed categorization based on system evaluation parameters is depicted in figure 2, in the form of 'red cross'. Each evaluation parameter is denoted by appropriate alphabet and each critical factor is provided a serial number. So, we can refer a particular critical factor with an alphanumeric index. For example, 'Emergency' can be referred as T9 and 'Evidence-based practice' is denoted as P3.

There is a major consensus on categorization of almost all critical factors with respect to system evaluation parameters. One physician has suggested additional critical factor - 'Protocols about diagnosis and treatment', which is not included in final list as its major aspects are covered by other relevant factors already included in listed critical factors.

\subsection{CATEGORIZATION BASED ON CONSTITUENTS OF PATIENT MANAGEMENT}

Table 3. Categorization of critical factors based on constituents of patient management

\begin{tabular}{|c|c|c|c|c|c|}
\hline Category & $\begin{array}{l}\text { Patient / } \\
\text { disease }\end{array}$ & Infrastructure & Medical device & $\begin{array}{l}\text { Physician } \\
\text { /staff }\end{array}$ & Administration \\
\hline $\begin{array}{l}\text { Response } \\
\text { Time } \\
\text { (T) }\end{array}$ & T6,T9,TIO & $\mathrm{T} 2, \mathrm{~T} 8$ & $\mathrm{~T} 2, \mathrm{~T} 5, \mathrm{~T} 8$ & $\begin{array}{c}\text { T1,T3,T4, } \\
\text { T5,T6,T7, } \\
\text { T8,T } 10\end{array}$ & T7,T8,TI 0 \\
\hline $\begin{array}{l}\text { Precision } \\
\text { (P) }\end{array}$ & $\mathbf{P 3}$ & $\mathbf{P} 2, \mathbf{P} 3$ & $\begin{array}{c}\text { P2, P3, P4, } \\
\text { P6 }\end{array}$ & $\begin{array}{c}\text { PI,P3, P5, } \\
\text { P7, P8 }\end{array}$ & P5,P7, P8 \\
\hline $\begin{array}{l}\text { Compre- } \\
\text { hension } \\
\text { (C) }\end{array}$ & C6 & $\mathrm{Cl}, \mathrm{C7}$ & $\begin{array}{l}\mathrm{Cl}, \mathrm{C} 2, \mathrm{C} 3, \\
\mathrm{C} 4, \mathrm{C} 5, \mathrm{C} 7\end{array}$ & $\begin{array}{c}\mathrm{Cl}, \mathrm{C} 2, \mathrm{C} 5 \\
\mathrm{C} 6\end{array}$ & $\mathrm{C} 5, \mathrm{C} 6$ \\
\hline $\begin{array}{l}\text { Efficiency } \\
\text { (E) }\end{array}$ & EI,E2, E3 & E6,E7 & E2, EIO & $\begin{array}{c}\text { EI,E2, E3, } \\
\text { E8,E9, EI 0, } \\
\text { EI } 3\end{array}$ & $\begin{array}{c}\text { EI,E4, E5, } \\
\text { E7,E9, EI I, } \\
\text { EI } 2, \text { EI } 3\end{array}$ \\
\hline
\end{tabular}

For improved and in-depth understanding of critical factors, two types of factor categorization (based on system evaluation parameters and constituents of patient management) are combined and represented in table 3. This table is constructed based on major constituents of patient management such as patient / disease, infrastructure, medical devices, physician / staff and administration. Also, the grey color shades are used to highlight an importance of a particular constituent and darker the shade, more significant is the parameter. For example, in a row for response time, a column associated with physician / staff is shaded in dark grey. It suggests that critical factors related with physicians or staff are more important for an evaluation parameter response time. It can be observed that the darker color shades have appeared more with columns of medical devices and physician / staff. It suggests that medical devices and physicians are most important constituents of patient management in ICU.

\subsection{CATEGORIZATION BASED ON USER INTERFACE (UI) DESIGN}

The third categorization of critical factors is based on on-screen user interface design of medical devices in ICU. With this perspective, categorization of critical factors is proposed derived from 
analytical discussion among the authors. The categories suggested, include factors relevant to 'User Interface', 'Work environment \& organizational culture' and 'Context'. The factors in the category of 'User Interface' are selected based on related physicians' survey. In this survey, physicians have been asked to select the critical factors significant in their interaction with medical devices using on-screen user interface. Table 4 provides a list of such critical factors along with related frequency, which represents number of physicians supporting its selection in category of 'User Interface'. In this list, two factors - 'Surveillance \& monitoring' and 'Room layout \& location of resources' have lesser frequency (one or two) and they are not included in the list of factors affecting user interface design. In fact, many aspects of "Surveillance \& monitoring' related with device interaction are covered in other selected factors - 'Effectiveness of display / UI design' and 'Design of alarms \& alerts'. Also, other factor - 'Room layout \& location of resources' is more relevant to category 'Work environment \& organizational culture' [16] rather than 'User Interface'. Therefore, table 5 shows final categorization of critical factors based on user interface design. It can be observed that factors related with a category of 'User Interface' are mainly related with staff interaction with medical devices, which is extremely important in patient care. This fact is similar to aviation industry in which the interaction between pilots and technology in cockpit is also critical [17, 18].

Table 4. Selection of critical factors related with UI design based on physicians' survey

\begin{tabular}{|c|c|c|c|c|c|}
\hline Index & Critical Factor & Freq. & Index & Critical Factor & Freq. \\
\hline $\mathrm{T} 2$ & Complex technology & 4 & $\mathrm{C} 1$ & $\begin{array}{l}\text { Complex work flow } \& \\
\text { information flow }\end{array}$ & 4 \\
\hline T3 & Multitasking & 4 & $\mathrm{C} 2$ & Information overload & 5 \\
\hline T5 & $\begin{array}{l}\text { Familiarity of equipment, } \\
\text { procedure or environment }\end{array}$ & 5 & $\mathrm{C} 3$ & $\begin{array}{l}\text { Effectiveness of display / UI } \\
\text { design }\end{array}$ & 5 \\
\hline T6 & Situation-specific quick fixes & 4 & $\mathrm{C} 4$ & Design of alarms \& alerts & 5 \\
\hline P1 & $\begin{array}{l}\text { Physicians with varying } \\
\text { levels of critical care training }\end{array}$ & 5 & C6 & Surveillance \& monitoring & 2 \\
\hline P3 & Evidence-based practice & 5 & E2 & $\begin{array}{l}\text { Type / amount / duration of } \\
\text { therapy }\end{array}$ & 4 \\
\hline P4 & $\begin{array}{l}\text { Correctness of default } \\
\text { thresholds }\end{array}$ & 5 & E6 & $\begin{array}{l}\text { Room layout \& location of } \\
\text { resources }\end{array}$ & 1 \\
\hline P6 & Equipment defect \& failure & 5 & E10 & Skills of nurses & 5 \\
\hline
\end{tabular}

A complete list of critical factors, which may affect the user interface design of medical devices, is depicted in Table 6. This table follows a same indexing as discussed in earlier categorization. For example, P3 is an alphanumeric index for critical factor - 'Evidence-based practice'. 
Table 5. Categorization of critical factors based on UI design

\begin{tabular}{|l|l|}
\hline \multicolumn{1}{|c|}{ Category } & \multicolumn{1}{|c|}{ Critical Factors } \\
\hline User Interface & T2,T3,T5, T6, \\
& PI,P3, P4, P6, \\
& CI-C4, \\
& E2, EI0 \\
\hline Work Environment \& & T4,T7,T8, T10, \\
Organizational Culture & P5, P7, P8, \\
& C5, C6, C7, \\
& E3-E5, E7-E9, EI I-I3 \\
\hline Context & TI,T9, \\
& P2, \\
& EI,E6 \\
\hline
\end{tabular}

Table 6. List of critical factors affecting UI design in medical devices

\begin{tabular}{|c|c|}
\hline $\begin{array}{c}\text { Complex technology } \\
\text { (T2) }\end{array}$ & $\begin{array}{c}\text { Multitasking } \\
\text { (T3) }\end{array}$ \\
\hline $\begin{array}{c}\text { Familiarity of equipment, procedure or } \\
\text { environment (T5) }\end{array}$ & $\begin{array}{c}\text { Situation specific quick fixes } \\
\text { (T6) }\end{array}$ \\
\hline $\begin{array}{c}\text { Physicians with varying levels of } \\
\text { critical care training (P1) }\end{array}$ & $\begin{array}{c}\text { Evidence-based practice } \\
\text { (P3) }\end{array}$ \\
\hline $\begin{array}{c}\text { Correctness of default thresholds (P4) } \\
\text { Complex work flow and information } \\
\text { flow (C1) }\end{array}$ & $\begin{array}{c}\text { Equipment defect and failure } \\
\text { (P6) }\end{array}$ \\
\hline $\begin{array}{c}\text { Effectiveness of display / Ul design } \\
\text { (C3) }\end{array}$ & $\begin{array}{c}\text { Design of alarms and alerts } \\
\text { (C4) }\end{array}$ \\
\hline Type / amount / duration of therapy \\
(E2)
\end{tabular}

\section{CASE STUDY RELATED WITH CRITICAL FACTORS}

For improved understanding of critical factors in ICU, a case study was followed with a given description: A middle-aged man had a history of a fall from height and was suffering from a head injury and multiple fractures. He was unconscious and required a ventilator support. The critical factors related with this case and a relationship among these factors is depicted in figure 3. This patient was brought to 'Casualty Department', where 'Medical Officer' provided him with primary resuscitation. Since patient's condition was highly critical, he was shifted to the ICU. Generally, a patient's bed position is decided based on one's criticality and he was provided one next to patient monitoring station in ICU for better surveillance. Physicians and nurses initiated the treatment and patient care. It was observed that a critical care training of physicians 
and nursing skills played crucial role during patient care. A staff familiarity with equipment, procedure and environment is important as it can affect the response time during emergency [19]. Physicians were involved in multiple tasks such as setting up medical devices, observing patient condition, interpreting patient record / EMR or performing medical procedures. Here, they interacted quite often with ventilator system or patient monitoring system through user interface. Occasionally, they were involved in situation specific quick fixes such as setting parameters of ventilator system, timely selection of ventilation mode depending on patient's parameters and providing alternative modes of oxygen as well as electric power supply.

ICU staff was dealing with complex technology related with medical devices. Depending upon patient condition, correct threshold values were set in devices through user interface. Sometimes, medical devices indicated changing patient conditions through alarms and alerts, which helped a staff in better patient monitoring. Few equipment defects and failures were also observed during patient care and they include inconsistent reading of patient parameters though automated probes, false alarms or poor visibility of displayed information from a distance [20]. Other critical factors such as display / UI design and complex work flow also affected the users' comprehension about patient condition or patient care.

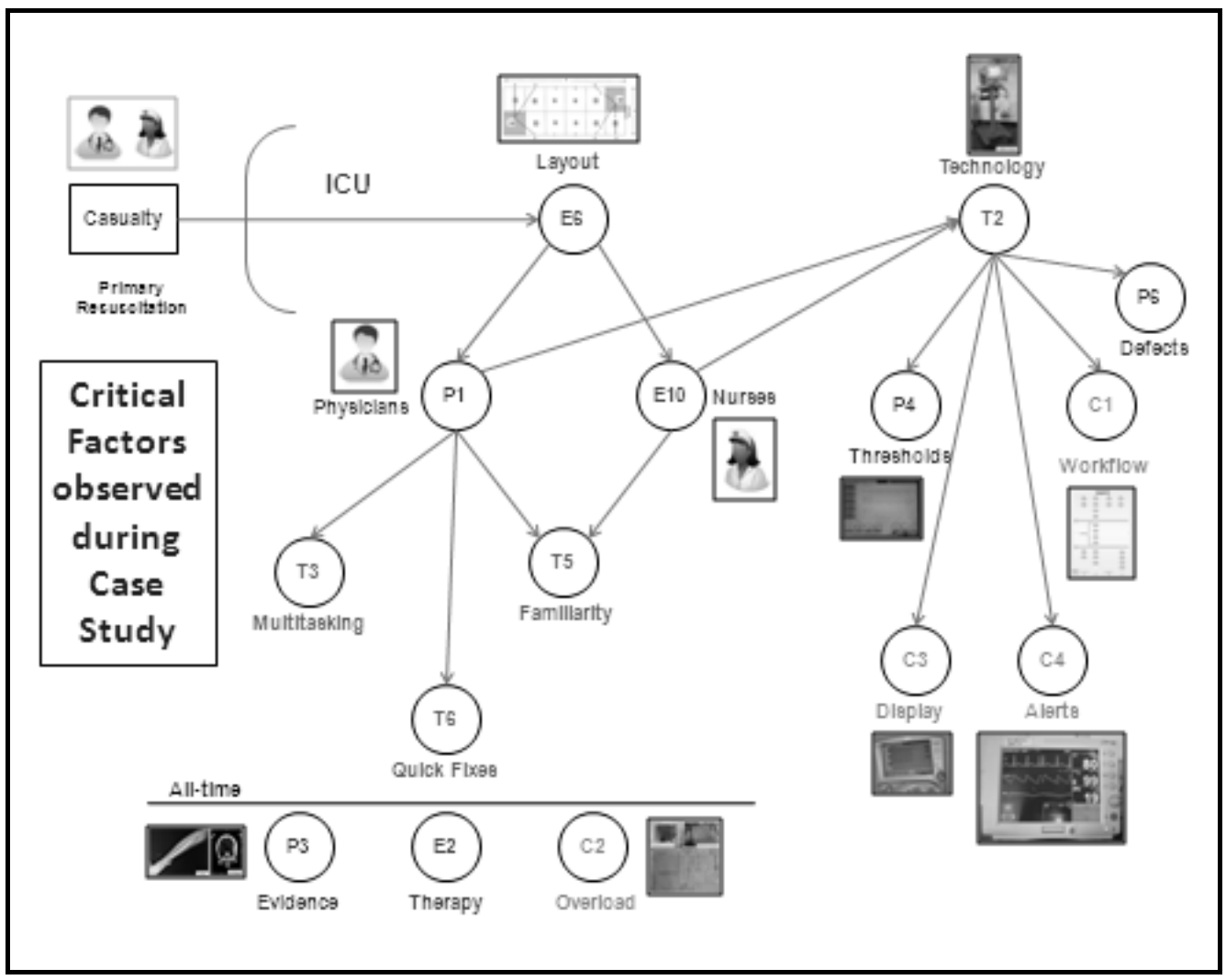

Figure 3. Case study depicting relationships among critical factors observed during study

Medical practice has become evidence-based practice [21] and a lot of evidences such as Electronic Medical Record (EMR) and paper reports were generated and followed during patient care. Many therapies were applied as per requirements such as surgical therapy (craniotomy), intra-medullary nailing [22] and physiotherapy, and some of them were aimed at long-term care. During patient care, a lot of information was generated in the form of EMR, diagnostic tests, 
readings / trends provided by devices and instructions on bed-side charts [23]. Often, it led to information overload; much of which was due to faulty user interface design.

The critical factors such as evidence-based practice, therapies applied and information overload affected patient care all-the time. Thus, such factors definitely need a special attention during user interface design of medical devices.

\section{CONCLUSIONS}

The overview of research publications through a literature survey has directed a selection of thirty eight critical factors, which are related with Intensive Care Unit. These factors are categorized by number of ways based on system evaluation parameters, constituents of patient management and user interface design. The physicians' survey has helped in categorization of critical factors into several relevant groups. The survey has also facilitated in identifying fourteen critical factors which mainly affect the user interface design of medical devices in ICU. The critical factors identified under the category - 'User Interface' include factors such as situation-specific quick fixes, evidence-based practice, information overload, equipment defect and failure, skills of nurses and others.

The identification and categorization of critical factors is extremely useful to several professionals. Device manufacturers and user interface designers will certainly apply them during various aspects of medical device design. ICU administrators and physicians will find them useful in ICU resource management. Such positive approach by professionals will minimize errors related with medical devices and ICU, improving the patient care.

\section{ACKNOWLEDGEMENTS}

We are grateful to Dr. G. G. Ray, Professor and Head at IDC, IIT, Bombay, India for his useful suggestions during research. We also appreciate a cooperation extended by various physicians like Dr. Ajit Adangale, Dr. Harshwardhan Anturkar, Dr. Gayatri Godbole, Dr. Shekhar Karmarkar and Dr. Rajiv Doshi along with the nursing staff during the field experimentation in ICUs. At last, we thank a photo-enthusiast, Ahmed Hamja for his support to research work through photography.

\section{REFERENCES}

[1] "ICU in changeover mode", (2003) Healthcare Management Express, 15-31 Aug.

[2] G. Bhutkar, D. Katre, N. Rajhans, S. Deshmukh (2008) "Scope of ergonomic and usability issues with Intensive Care Unit (ICU): an Indian perspective”, HFESA Journal - Ergonomics Australia, 22(1), pp 26-32.

[3] R. Fairbanks (2004) "Poor interface design and lack of usability testing facilitate medical error", Joint Commission Journal on Quality and Safety: Human Factor Engineering Series, 30, pp 579-584.

[4] G. Bhutkar, D. Katre, N. Rajhans (2008) "Usability survey of medical devices used in ICU", Journal of HCI Vistas, IV.

[5] J. Martin, E. Murphy, J. Crowe, B. Norris (2006) "Capturing user requirements in medical device development: the role of ergonomics", Physiological Measurement, 27(8), pp 49-62.

[6] P. Gokin (2005) "Human factor issues in designing alarms and monitors for critical care environments", Course HF 755B.

[7] M. Smith, J. Higgs, E. Ellis. "Factors influencing clinical decision making. Chapter 8, pp 89-100.

[8] A. Konkani, B. Oakley (2012) "Noise in hospital intensive care units-a critical review of a critical topic", Journal of Critical Care, 27(5), pp 522.e1-522.e9. 
[9] N. Staggers, M. Troseth and Group. "Designing usable clinical information systems", The Tiger Initiative Usability Report, pp 1-25.

[10] T. Reader, R. Flin, K. Launche, B. Cuthbertson (2006) "Non-technical skills in the intensive care unit", British Journal of Anaesthesia, 96, pp 551-559.

[11] Y. Demir, E. Korhan, I. Eser, L. Khorshid (2013) "Factors affecting experiences of intensive care patients in Turkey: patient outcomes in critical care setting", Journal of Pakistan Medical Association, 63(7), pp 821-825.

[12] C. Kothari (2010) "Research methodology - methods and techniques", New Age International Publishers, New Delhi, 2, pp 14-17.

[13] G. Bhutkar, N. Rajhans, D. Katre, P. Dhabe, M. Dhore, B. Barbadekar (2010) "Analysis and design of ICU Knowledge Management System (IKMS) for Indian environment with usability perspective", Proceedings of IEEE ICCAE 2010, Singapore, 2, pp 329-333.

[14] Performance analysis Available at: http://www.hit.ac.il/staff/leonidm/information-systems/ch78.html. Retrieved on January 31, 2013.

[15] Definitions of system evaluation parameters Available at: http://medicaldictionary.thefreedictionary.com. Retrieved on January 21, 2013.

[16] Hospital management Available at: http://www.nou.edu.ng/noun/NOUN_OCL/pdf /pdf2/MPA\%20773\%20Hospital\%20Management.pdf. Retrieved on January 31, 2013.

[17] E. Hutchins (1995) "How a cockpit remembers its speed", Cognitive Science, 19, pp 265-288.

[18] J. Zhang, V. Patel, E. Shortliffe, M. Shabot, D. Rucker (2005) "Cognitive factors and decision making in critical care environments", AMIA Symposium.

[19] T. Buckley, T. Short, Y. Rowbottom, T. Oh (1997) "Critical care reporting in intensive care unit", Anaesthesia, 52, pp 403-407.

[20] G. Bhutkar, D. Katre, G. Ray, S. Deshmukh (2013) "Usability model for medical user interface of ventilator system in intensive care unit", Human Work Interaction Design, Work Analysis and HCI, IFIP AICT 407, Springer, pp 46-64.

[21] E. Luk, L. Rose (2011) "Conducting a large survey of critical care nurses in Canada: lessons learnt", Intensive and Critical Care Nursing, 27, pp 173-179.

[22] A. Starr, J. Hunt, D. Chason, C. Reinert (1998) "Treatment of femur fracture with associated head injury", Journal of Orthopaedic Trauma, 12, pp 38-45.

[23] T. Heldt, B. Long, G. Verghese, P. Szolovits, R. Mark (2006) "Integrating data, models and reasoning in critical care", Proceedings of 28th IEEE EMBS Annual International Conference, New York, USA, pp 350-353.

[24] D. Wong, W. Knaus (1991) "Predicting outcomes in critical care: APACHE prognostic scoring system", Canadian Journal of Anaesthesia, 38, pp 374-383.

[26] E. Azoulay et al. (2009) "Prevalence and factors intensive care unit conflicts: the conflicus study", American Journal of Respiratory and Critical Care Medicine, 180, pp 853-860.

[27] E. Camire, E. Moyen, H. Stelfox (2009) "Medication errors in critical care: risk factors, prevention and disclosure", Canadian Medical Association Journal, 180, pp 936-943.

[28] E. Manias, A. Street (2001) "The interplay of knowledge and decision making between nurses and doctors in critical care", International Journal of Nursing Studies, 38, pp 153-161.

[29] F. Hicks, S. Merritt, A. Elstein (2003) "Critical thinking and critical decision making in critical care nursing”, Heart \& Lung, 32, pp 169-180.

[30] H. Bush, W. Barr (1997) "Critical care nurses' lived experiences of caring”, Heart \& Lung, 26, pp 387-398.

[31] J. Badger (2005) "Factors that enable or complicate end-of-life transitions in critical care", American Journal of Critical Care, 14, pp 513-521.

[32] J. Rothschild et al. (2005) "The critical care safety study: the incident and nature of adverse events and serious medical errors in intensive care", Critical Care Medicine, 33, pp 1694-1700.

[33] M. Garrouste-Orgeas, L. Montuclard, J. Timsit, B. Misset, M. Christias, J. Carlet, "Triaging patients to the ICU: a pilot study of factors influencing admission decisions and patient outcomes", Intensive Care Medicine, 29, pp 774-781.

[34] P. Benner, R. Hughes, R. Sutphen. "Clinical reasoning, decision making and action: thinking critically and clinically", Patient Safety and Quality: An Evidence-based Handbook for Nurses.

[35] S. Cartledge S. (2001) "Factors influencing the turnover of intensive care nurses", Intensive and Critical Care Nursing, 17, pp 348-355. 
[36] S. Quimet, B. Kavanagh, S. Gottfried, Y. Skrobik (2007) "Incidence, risk factors and consequences of ICU derilium", Intensive Care Medicine, 33, pp 66-73.

[37] T. Wenham, A. Pittard (2009) "Intensive care unit environment", British Journal of Anaesthesia: Critical Care and Pain, 9, pp 178-183.

[38] V. Patel, T. Cohen (2008) "New perspectives on error in critical care", Critical Care, 8(14), pp 456459.

[39] W. Chaboyer, W. Najman, S. Dunn (2001) "Factors influencing job valuation: a competitive study of critical care and non-critical care nurses", International Journal of Nursing Studies, 38, pp 153-161.

[40] Y. Chen, S. Lin, C. Liu, D. Jiang, P. Yang, S. Chang (2001) "Risk factors for ICU mortality in critically ill patients", Journal of the Formosan Medical Association, 100, pp 656-61.

\section{Authors}

Ganesh Bhutkar is M. E. (Comp. Engg.) and MBA from University of Pune, India. He is Assistant Professor at Vishwakarma Institute of Technology (VIT), Pune. Also, he is currently pursuing $\mathrm{PhD}$ in Medical Usability at Industrial Design Centre (IDC), Indian Institute of Technology (IIT), Bombay. He has about 18 years of academic and research experience. His areas of interest are Human Computer Interaction (HCI), Information Systems and Healthcare Applications.

Dr. Dinesh Katre is Associate Director at C-DAC, Pune, India and presently heading the Human-Centred Design and Computing (HCDC) Group. He is PhD in Human Computer Interaction (HCI) from Birla Institute of Technology and Science (BITS), Pilani and Master of Design from IDC, IIT, Bombay. He has about 20 years of professional experience related to Design, Usability Research and Information Technology

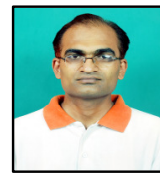
Applications.

Dr. Shahaji Deshmukh is a Professor of Surgery at Bharati Vidyapeeth University Medical College (BVUMC), Pune, India. He has 22 years of teaching and administrative experience of managing 800 bedded teaching hospital. During these years, he has planned extensive upgrades and additions of new departments in the medical college hospital. He is also a teacher of Healthcare Management. He has a portal on hospital planning and can be

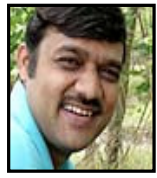
contacted for further assistance and consultancy. (http://www.hospitalplanning.net). 